\title{
ЭКОНОМИЧЕСКАЯ ОЦЕНКА ПРИМЕНЕНИЯ ОТХОДОВ ПРОМЫШЛЕННОСТИ В ПРОИЗВОДСТВЕ ДОРОЖНО-СТРОИТЕЛЬНЫХ МАТЕРИАЛОВ
}

\author{
(c) 2020 Толстихина Екатерина Дмитриевна \\ студент магистратуры кафедры строительные материалы и технологий строительства \\ Сибирский федеральный университет, Россия, Красноярск \\ E-mail: tolstihina@yandex.ru \\ (c) 2020 Брыжатый Даниил Ринатович \\ студент магистратуры кафедры строительные материалы и технологий строительства \\ Сибирский федеральный университет, Россия, Красноярск \\ E-mail:bruzhatui@yandex.ru \\ (c) 2020 Шмидт Максим Ильич \\ студент специалитета кафедры «Строительство уникальных зданий и сооружений» \\ Сибирский федеральный университет, Россия, Красноярск \\ E-mail: maks.shmidt.01@list.ru \\ (c) 2020 Кудусов Абдурахмон Абдусаломович \\ студент кафедры инженерных систем зданий и сооружений \\ Сибирский федеральный университет, Россия, Красноярск \\ E-mail: qudusov2002@mail.ru \\ (c) 2020 Кременская Екатерина Александровна \\ студент специалитета кафедры «Строительство уникальных зданий и сооружений» \\ Сибирский федеральный университет, Россия, Красноярск \\ E-mail: ekaterina.kremenskaya@gmail.com
}

Обширное использование традиционных каменных материалов в дорожном строительстве ограничивается их дефицитом и высокой стоимостью. Одним из способов решения данной проблемы является применение отходов производства, модифицированных различными добавками разной природы. На сегодняшний день, в отвалах накоплено около 1,5 млрд.т. золошлаковых отходов и более 120 млн. $\mathrm{m}^{3}$ отсевов дробления, что неизбежно сказывается на рельефе местности и значительном ухудшении экологической ситуации.

В связи с этим в данной статье была рассмотрена возможность сокращения себестоимости дорожно-строительных материалов благодаря использованию в их составе отходов промышленности.

Ключевые слова: дорожно-строительные материалы, отходы промышленности, сокращение себестоимости строительных материалов, экономия, производство строительных материалов.

На сегодняшний день тема вторичной переработки промышленных отходов актуальна и объединяет в себе вопросы ресурсосбережения и сохранения окружающей среды. Рациональным способом утилизации отходов промышленности может стать его повторное использование в качестве исходного материала для производства различной строительной продукции и изделий. Такой подход является одним из самых рациональных способов утилизации производственных отходов, благодаря которому удастся удовлетворить около $40 \%$ потребности в сырьевых материалах, необходимых для строительства дорог по всей стране.

Внедрение дешевых сырьевых ресурсов в состав дорожно-строительных материалов дает возможность улучшить качество дорожной одежды, следствием чего будет являться увеличение срока эксплуатации, что в долгосрочной перспективе приведет к снижению расходов на ремонтные работы и обслуживание дорожных покрытий. Строительство автомобильных дорог связано с большим объемом потребления материалов, что приводит к увеличению количества 
необходимых для производства сырьевых компонентов. Применение переработанных отходов промышленности в процессе изготовления материалов для строительства дорог приведет к снижению стоимости готовых дорожностроительных материалов и сбережению природных ресурсов [1].

Сегодня проблема утилизации отходов производства носит глобальный характер и неразрывно связана с их вторичным применением в качестве сырья. Каждый год в России в процессе производства образовывается свыше 3 млрд.т. отходов. Около 93\% из которых, составляют отходы топливно-энергетических предприятий. Менее 7\% от общего объема отходов приходится на другие виды экономической деятельности: обрабатывающие предприятия, производство и распределение электроэнергии, газа и воды, строительство, сельское хозяйство.

По данным Федеральной службы по надзору в сфере природопользования за 2019 год отходы по различным отраслям составили свыше 7 млн. тонн. В сравнении с 2016 годом количество отходов увеличилось почти в 1,5 раза.

Среднее значение коэффициента повторного использования отходов промышленности в России оценивается примерно в одну треть, в отличие от европейских стран и США, где этот показатель в 2-2,5 раза выше. При этом, стоит учесть, что в Российской Федерации большая часть отходов от производства и потребления почти не применяется в хозяйственной деятельности. Это демонстрирует уровень вторичной обработки ТБО (твердых бытовых отходов), который по всей стране колеблется от $4 \%$ до $5 \%$. К списку плохо перерабатываемых отходов относятся золы, шлаки, изношенные автомобильные шины, а также различные отходы полимеров и.т.д.

Образование и дальнейшее обращение с отходами должны быть задокументированы и учтены в соответствии с Порядком учета в области обращения с отходами. Учет отходов на предприятии производится за счет заполнения журнала.

Журнал первичного учета отходов является документов отчета и служит для хранения данных о перемещении отходов на предприятия. На основе данного журнала каждый год разрабатывается отчетность и документация.

На момент 2020 года заполнение журнала первичного учета отходов регламентировано Приказом Минприроды РФ № 721 «Об утверждении Порядка учета в области обращения с отходами».

Из этого следует, что для реализации требований данного приказа на каждом промышленном предприятии, в котором формируются отходы, необходимо вести соответствующий журнал, который отражает все факты образования и передвижения остатков производства.

В журнале принимаются к сведению все от-

Таблица 1. Образование отходов производства и потребления по видам экономической деятельности по РФ

\begin{tabular}{|l|c|c|c|c|}
\hline \multicolumn{1}{|c|}{ Всего } & 2016 & 2017 & 2018 & 2019 \\
\hline \multicolumn{1}{|c|}{} & $\mathbf{5 4 4 1 3 1 3 , 5}$ & $\mathbf{6 2 2 0 6 4 3 , 4}$ & $\mathbf{7 2 6 6 0 5 4 , 0}$ & $\mathbf{7 7 5 0 8 7 7 , 3}$ \\
\hline производство пищевых продуктов & 21054,7 & 26264,4 & 19277,9 & 17480,9 \\
\hline производство текстильных изделий & 266185,8 & 6072,3 & 37,0 & 41109,7 \\
\hline производство одежды & 4257,1 & 1580,0 & 290,6 & 686,3 \\
\hline $\begin{array}{l}\text { производство бумаги и бумажных } \\
\text { изделий }\end{array}$ & 4592,1 & 5545,6 & 6260,4 & 5560,8 \\
\hline $\begin{array}{l}\text { производство химических веществ } \\
\text { и химических продуктов }\end{array}$ & 14157,5 & 38731,6 & 45972,1 & 42250,1 \\
\hline $\begin{array}{l}\text { производство резиновых и пласт- } \\
\text { массовых изделий }\end{array}$ & 273,2 & 271,0 & 250,8 & 291,7 \\
\hline $\begin{array}{l}\text { производство прочей неметалличе- } \\
\text { ской минеральной продукции }\end{array}$ & 25184,5 & 15110,4 & 19928,9 & 14875,5 \\
\hline производство металлургическое & 190626,0 & 150802,2 & 136065,2 & 155308,7 \\
\hline $\begin{array}{l}\text { производство готовых металли- } \\
\text { ческих изделий, кроме машин и } \\
\text { оборудования }\end{array}$ & 3434,8 & 3304,2 & 1000,4 & 1391,8 \\
\hline $\begin{array}{l}\text { производство компьютеров, элек- } \\
\text { тронных и оптических изделий }\end{array}$ & 2099,2 & 304,9 & 378,1 & 777,7 \\
\hline
\end{tabular}


ходы предприятия, начиная с I по V класс опасности. Данный документ обязан заполнять сотрудник, отвечающий за обращение с опасными остатками производства [2].

Согласно Приказу № 721 все юридические лица и индивидуальные предприниматели должны вести журнал учета отходов.

Взяв на основу расчета объем то, что выбрасывают жители нашей страны и остатки от производства, то получится всего 5\% того, что проходит вторичную переработку. Принимая факт о том, что объемы твёрдых бытовых отходов (ТБО) с каждый годов растут на 10\%, становится явным прогресс увеличения отходов за счет того, что количество прироста во много раз превышает масштабы утилизации.

Практика Швеции показала, что возможно перерабатывать 99\% отходов и получать прибыла за счет рационального применения вторичного сырья.

На сегодняшний день Министерство природы РФ планирует реализовать масштабный проект по строительству фабрик сжигания мусора. По прогнозам, его реализация будет окончена в 2030 году.

Достоинством сжигания отходов заключается в отсутствие потребности сортировки мусора, а недостатком является нерациональное использование мусора. Сортировка дает возможность найти из общего объема отходов полезные компоненты, которые благодаря обработки могут быть использованы в разных областях промышленности (например, в строительстве дорог).

В Российской Федерации на момент 2020 года применяется ряд методов утилизации отходов, в зависимости от их типа:

- захоронение;

- компостирование;

- плазменная переработка;

- сжигание.

В качестве вторичных материалов можно рассматривать не только отходы производства, но также отходы потребления. Кроме того, они могут применяться как в хозяйственных целях, так и частично или полностью заменить традиционные материально-сырьевые и топливноэнергетические ресурсы. Помимо этого, основным свойством такого вида ресурсов считается их непрерывная воспроизводимость.

Замена дорогостоящих высокопрочных каменных материалов грунтами, укрепленными вяжущим на основе отходов производства и по- требления, в конструктивных слоях оснований и устройстве тонкослойных покрытий для дорог 4 и 5 технических категорий позволит снизить не только экологическую нагрузку в регионах Российской Федерации, но и стоимость строительства.

Не одно десятилетние исследователи и ученые-дорожники в своей деятельности уделяли внимание этому вопросу, однако широкого применения отходов промышленности достичь не удалось. Данный процесс сдерживают следующие факторы:

- различия в свойствах одинаковых отходов;

- необходимость предварительной подготовки;

- необходимость совершенствования технологии.

Различия в свойствах одинаковых отходов обусловлены прежде всего различиями в технологии производства (компоненты, условия и т.д.) основного продукта.

Помимо этого использование отходов носит региональный характер, экономическая эффективность в большей степени обусловлена дальностью транспортировки отхода. Региональный характер также снижает и эффективность научных исследований в данном направлении, так как во многих случаях исследователи практически ничего не знают об отходах отдаленных производств и при повторном обращении к отходу другим исследователем заново производится весь комплекс исследований (спектральный анализ, микроскопия и т.д.). Для повышения эффективности использования отходов промышленности необходимо в первую очередь создать республиканскую базу данных, содержащую полную и исчерпывающую информацию о таких материалах. Обновление информации требуется только при изменении состава или исходных компонентов и технологии основного производства. Увеличения числа исследователей, обращающихся к такому роду информации, позволит увеличить вероятность успешного решения проблемы [1].

Ни один из известных отходов промышленности не может быть использован при производстве дорожно-строительных материалов без предварительной обработки. Многие отходы хранятся под открытым небом и поэтому нуждаются в сушке, удалении различных примесей и т.д., например, волокнистые отходы не- 
обходимо вспушивать перед использованием, а также обрабатывать поверхностно-активными веществами для повышения адгезии с вяжущим.

Введение нового компонента в состав дорожно-строительного материала в большинстве случаев вызывает необходимость изменения технологического процесса приготовления.

Ликвидация всех недостатков применения отходов в производстве дорожно-строительных материалов приведет к увеличению стоимости дорожно-строительного материала. Экономическая эффективность будет определятся не только снижением затрат на приобретение материала, замещаемого отходом промышленности, и возможным продлением срока службы дорожной конструкции, но и за счет такого неявного показателя как экологическая эффективность. Под экологической эффективностью понимается сокращение затрат на хранение и утилизацию отходов производств. Второй важной особенностью замещения части традиционных материалов отходами промышленности является получение материала с недостаточными физико-механическими и другими свойствами. В таком случае целесообразно провести дополнительные исследования, направленные на поиск других условий применения такого материала. В качестве примера можно привести проблему использования песчаного асфальтобетона в качестве несущего слоя дорожного покрытия. Несколько десятилетий исследователи не обращали внимание на варианты использования песчаных асфальтобетонов в качестве материала для тонкого защитного слоя или трещинопрерывающей прослойки. В таком случае низкая сдвигоустойчивость практически не проявляется.

На сегодняшний день в нашей стране в эксплуатации находятся более 30 тыс.км. в автомобильных дорог, которые построены с использованием укрепленных грунтов. Для сравнения, мировой показатель полотен, построенных с применением конструктивных слоев из укрепленных грунтов на автомобильных дорогах и

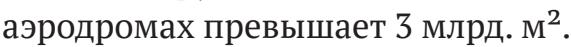

При этом наибольший интерес в качестве компонентов для производства дорожностроительных материалов представляют отходы нефтяной, металлургической, химической промышленности и отходы тепловых электростанций:

1. Золы и шлаки ТЭС и ТЭЦ. На сегодняш- ний день общий объем золошлаковых отходов в нашей стране можно соотнести с крупным техногенным месторождением. В Российской Федерации проведено множество исследований, в которых рассмотрено применение золошлаковых отходов при устройстве слоев земляного полотна и дорожной одежды. Кроме этого, имеется опыт использования золы улавливая сухим методов в качестве добавок к битумам, полимерно-битумным вяжущим (ПБВ), а также в роли самостоятельного материала, обладающего свойством замедленного твердения. Но объемы переработки этих отходов в настоящее время составляют не более 20\%. В основном зола используется в качестве наполнителя для цементов, причем 1,3 т. золы-уноса бурого угля, уловленной из дымовых газов, заменяет 1 т. цемента.

2. Отходы полимеров могут использоваться для производства асфальтополимербетона, который имеет ряд преимуществ перед асфальтобетоном. Асфальтополимербетон отличается большей деформативностью при низких температурах, тем самым делая асфальтополмербетон более долговечным. Использование отходов полимеров повысить его эксплуатационные качества, решить важную экологическую проблему, связанную с утилизацией отходов, и снизить расход битума, что особенно важно в настоящее время в условиях роста цен и дефицита нефтяного сырья [3].

3. Сульфатсодержащие отходы химического производства плавиковой кислоты (фторгипс). В естественном состоянии фторгипс не проявляет вяжущие свойства. Дегидратация при температуре $160-1600{ }^{\circ} \mathrm{C}$ приводит к появлению вяжущих свойств. Применение фторангидрита может быть особенно эффективным при укреплении песчаных грунтов, песчано-гравийных и золошлаковых смесей.

4. Фосфогипс. На сегодняшний день в отвалах промышленных предприятий нашей страны накоплено около 200 млн. тонн фосфогипса и с каждым годом объем «запасов» увеличивается на 10-15 млн. тонн. Фосфогипс, как и фторгипс, представляет собой двуводный сульфат кальция и может применяться в качестве вяжущего для укрепления грунтов.

5. Нефтешламы (отходы нефтеперерабатывающей промышленности). Нефтешламы являются сложной физико-химической смесью, в состав которой входят нефтепродукты, механи- 
ческие примеси (глины, окислов металлов, песка) и вода. Процентный состав этих компонентов может быть различен в зависимости от вида нефлешлама [4].

6. Сера. Так же, как и нефтешлам, это отход нефтеперерабатывающей промышленности. Строительные материалы на основе серы обладают рядом положительных свойств, к которым относятся: быстрый набор прочности, обусловленный скоростью остывания смеси, относительно высокая прочность при сжатии (до $60 \mathrm{MПа),} \mathrm{стойкость} \mathrm{к} \mathrm{воздействию} \mathrm{агрессив-}$ ных сред, гидрофобность, низкое водопоглощение. следовательно, высокая морозостойкость. Одним из недостатков серы как вяжущего является усадка, обусловленная фазовым переходом серы из жидкого состояния в твердое. Использование различных химических модификаторов позволяет стабилизировать серное вяжущее. На сегодняшний день предложен ряд добавок, из которых наиболее эффективными являются дорожный битум, полистирол и стирол, полиорганополисульфиды (тиоколы и тиоколоподобные полимеры), позволяющие снизить негативные последствия уменьшения объема при фазовых переходах и температуру размягчения серных композиций [5].

Таким образом, решением проблем рационального ресурсопотребления может являться увеличение объема использования отходов производства и потребления в строительной отрасли, в частности при строительстве, реконструкции, капитальных ремонтных работах и ремонте автомобильных дорог, что также приведет к снижению себестоимости готового продукта. В свою очередь, этот факт обеспечит доступность данных материалов.

Очевидно, что дорожное строительство сопряжено с большим объемом потребления различных строительных материалов, в том числе каменных материалов с высокими марками по дробимости, истираемости и морозостойкости. Традиционно в конструкциях дорожных одежд применяются слои покрытия из горячих асфальтобетонных смесей на основе высокопрочных каменных материалов.

Учитывая вышесказанное, можно сделать вывод, что использование отходов производства и потребления в конструктивных слоях дорожных одежд и земляного полотна автомобильных дорог способствует решению следующих основных задач:

1) экономии сырьевых ресурсов;

2) переработка промышленных отходов и потребления;

3) улучшения экологической обстановки в регионах Российской Федерации;

4) снижения стоимости строительства, реконструкции и капитального ремонта автомобильных дорог;

5) увеличение срока эксплуатации дорожного полотна;

Применение отходов промышленности в процессе производства материалов для строительства дорог позволит сократить затраты до 30\%, что в сравнении с применением в производстве традиционного сырья составит экономию капитальных сложений в 35-50\%. Кроме того, применение остаточных продуктов производства дает возможность развивать не только традиционные, но и новые ресурсосберегающие строительные материалы. Данный вид обладает улучшенными техническими характеристиками и отличается меньшей ресурсоемкостью.

Таким образом, за счет применения отходов промышленности в производстве дорожностроительных материалов происходит сокращение затрат на исходные сырьевые ресурсы, тем самым повышается экономическая эффективность. Помимо этого, использование отходов как нового компонента в составе традиционных материалов стимулирует развитие и совершенствование отрасли производства дорожно-строительных материалов, что попутно благополучно влияет на окружающую среду.

\section{Библиографический список}

1. Александров Д.Ю. Проблема эффективного использования промышленных отходов при производстве дорожно-строительных материалов/ Д.Ю.Александров // Молодежь и научно-технический прогресс.2020 - с. $9-11$

2. Учет отходов на предприятии в 2020 году [Электронный ресурс] URL: https:/center-yf.ru/data/stat/uchetotkhodov-na-predpriyatii-v-2020-godu.php (Дата обращения 1.09.2020) 
3. Загидуллин А.И., Халилов Р.Х. Вторичная переработка отходов производства многослойных полимерных пленок, изготовленных из полярных и неполярных полимеров/ А. И. Загидуллин, Р. Х. Халилов/ Актуальные проблемы науки о полимерах. - 2020 - с. 117

4. Метликин 3.П. Применение нефтешламов в дорожном строительстве/ 3. П. Метликин / Новые технологии нефтегазовому региону. - $2018-$ с. $78-80$

5. Кондратьев А.С., Жирнов Б.С. Современные направления применения серы в дорожном строительстве / А. С. Кондратьев, Б. С. Жирнов/ Нефтеперерабатывающая и нефтехимическая промышленность. Обзорная информация. Серия: нефтехимия. - 2018 - № 2 - с. $43-49$ 